\title{
The use of transverse connectors as reinforcement of multi-leaf walls
}

\author{
Marco Corradi · Antonio Borri · Elena Poverello $\cdot$ Giulio Castori
}

Received: 27 April 2016/Accepted: 30 November 2016/Published online: 20 December 2016

(C) The Author(s) 2016. This article is published with open access at Springerlink.com

\begin{abstract}
The need for new retrofitting techniques is the consequence of an increasing interest in the conservation of historic construction. The global behavior of a stone masonry structure is often governed by the level of connection between masonry wall leaves and the overall quality of the masonry material. This paper presents the results of an investigation carried out on site and in the laboratory on multi-leaf stone masonry panels strengthened using stainless steel rod inserted in a grouted fabric sleeve. The aim is to increase the collaboration between weakly connected masonry leaves. Pull-out tests were conducted on site on full-scale stone masonry wall panels, with the aim of studying the force required to pull out a connector under uniaxial tension. Several wall panels were assembled in the laboratory using solid calcareous stones and weak mortar and the effectiveness of the connectors was tested in shear and compression on both virgin and damaged panels. The experimental tests allowed the analysis of the behavior of the multi-leaf panels. Experimental results show that a substantial improvement of the wall panels'
\end{abstract}

M. Corradi $(\square)$

Mechanical and Construction Engineering Department, Northumbria University, Wynne-Jones Building,

Newcastle upon Tyne NE1 8ST, UK

e-mail: marco.corradi@northumbria.ac.uk

M. Corradi · A. Borri - E. Poverello · G. Castori Department of Engineering, University of Perugia, Via Duranti, 93, 06125 Perugia, Italy mechanical behavior can be achieved by applying transverse connectors.

Keywords Wall panels $\cdot$ Strengthening methods · Connections $\cdot$ Masonry $\cdot$ Mechanical testing

\section{Introduction}

Historic Unreinforced Masonry (URM) building stock in many parts of the world are made of stone or brick masonry multi-leaf walls. Masonry wall panels in historic constructions were designed in the past to resist only vertical compression loads as historic masonry is characterized by high compressive strength. However seismic forces often cause the collapse or an important damage in historic constructions [1-4].

A large part of the building stock is listed by local conservation bodies, but many historic constructions are not actually protected. These are nevertheless an important part of the heritage architecture and new retrofit and cost-efficient solutions must be identified to mitigate their seismic vulnerability.

Prior structural analysis of historic constructions has been mainly focused on the analysis of the in-plane behavior of masonry wall panels potentially due to a reluctance to address the difficulties of out-of-plane tests and analyses. Significant progress has been recently made in understanding the in-plane behavior 
of historic masonry. The use of both "traditional" and new materials (composite materials, steel fibres, titanium alloys, etc.) has been studied and experimentally tested with the aim of increasing the masonry shear strength and stiffness properties. Surface reinforcement using steel/aluminum meshes, grout injections, deep repointing of mortar joints are examples of traditional reinforcement techniques [5-8].

Among new retrofitting methods, substantial research has been also conducted on reinforcing wall panels with composite materials [9-13]. Many critical issues have been recently investigated, including ensuring a durable bond between the FRP (Fiber Reinforced Polymer) and masonry substrate given the degradation effects due to ageing effects. This is very dependent on the type of FRP used for reinforcement.

As stated above, the effectiveness of these reinforcement techniques has been mainly validated with regard to in-plane loading. The out-of-plane behaviour received less attention with few studies present in the literature [14-17]. In this context, an important aspect is the analysis of multi-leaf stone masonry walls: this masonry typology is very common in historic constructions and its behavior under both vertical and horizontal actions is usually unsatisfactory: vertical stresses may differently distribute across the masonry leaves and this could also cause buckling problems.

Because barely cut and pebble stone masonry are usually constituted by several adjacent leaves, a multileaf wall performs poorly when subjected to horizontal forces. These multi-leaf walls are usually very vulnerable to out-of-plane actions, produced, for example, by soil pressure, wind or earthquake [18-20].

Since the out-of-plane behavior of masonry structures is mainly governed by simple boundary conditions and rotational equilibrium equations, previous research on the analysis of the mechanical properties of the masonry material supplemented by numerical models and laboratory studies, has limited relevance: masonry mechanical parameters (shear and compressive strengths, elastic moduli) do not govern the overall out-of-plane behavior of a slender masonry wall panel. For example the application of a vertical compressive load may have a positive effect on the out-of-plane behavior since it stabilizes the wall. For a multi-leaf wall, the out-of-plane mechanism often involves the external (outdoor) unconfined masonry leaf being vulnerable to horizontal actions (Fig. 1).

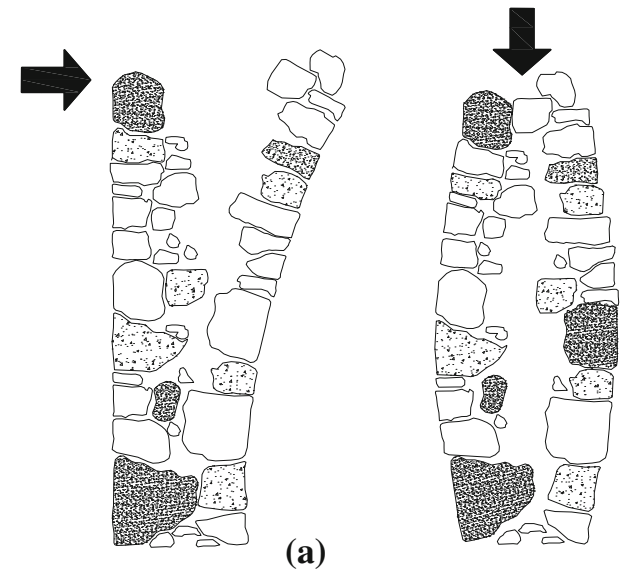

(b)

Fig. 1 a Failure mechanism of a double-leaf wall panel subjected to a horizontal load. b Failure mechanism of a panel subjected to a compression vertical load

In this context, the level of bonding between masonry leaves is an important aspect to consider. Connections (headers) can be made of large stones placed transversally: these elements may also contribute to a uniform distribution of compressive stresses. The presence of headers may cause an increase of the wall's capacity to resist seismic actions and it represents an important parameter to assess the masonry quality. Recently Borri et al. [19] introduced a visual non-destructive method to estimate the masonry quality. The presence and number of headers is one the main factors to consider. To study the level of bonding between adjacent leaves, the authors proposed the use of the "minimum length ratio". This non-dimensional value is the ratio between the minimum distance of two points A and B on the vertical wall cross section passing only through mortar joints and the straight distance between the two points.

Several other experimental researches have addressed the importance of the presence of transversal connections for multi-leaf walls and their considerable effect on the out-of-plane behavior [21-28]. In is known that an effective method to improve the outof-plane behavior of multi-leaf walls is to insert new headers. This could be made using new stones or bricks, or with steel or RC (Reinforced Concrete) elements. However limited research has been done in this area, mainly for the difficulty in reproducing historic masonry and in performing out-of-plane tests [29-31]. The insertion of new transverse connections is a difficult task since hollow steel tubes (core drills) 
are often used to drill holes in the masonry material: this causes a stress re-distribution in the area around the hole leaving this area uncompressed. Without an adequate interlocking, the new connector cannot act efficiently and its application could result ineffective.

This paper presents the results of an investigation on the use of artificial connectors made of a stainless rod inserted into a grouted fabric sleeve. By injecting with pressure the grout, it is possible to increase bonding with masonry and restore the stress state in the area around the hole. The main objective of this study was to assess the relationship between the connectors and the surrounding masonry material and to measure the increase in the mechanical behavior of the reinforced or repaired wall panels. By conducting on site pull-out tests it was possible to study the local effect of the application of the connectors, while the global effect was mainly analyzed by doing shear and compression laboratory tests.

\section{The connectors}

The strengthening system consisted in a SAE 304 (or AISI 304) stainless steel rod inserted in a fabric sleeve (Fig. 2). Wall panels were drilled from one side only with full-thickness holes. A diamond core drill bit was used to remove a cylinder of existing masonry material. Connectors were made of a solid stainless steel rod, with a diameter of 12,16 or $20 \mathrm{~mm}$, encased in a fabric sleeve injected with a cement-based grout. The choice of rod diameter depended on many factors like the magnitudes of the acting loads, the wall's thickness and on the quality of the masonry material.

In order to activate a mechanical interlocking between the new connector and the masonry substrate, the hole was countersunk at both ends up to a diameter

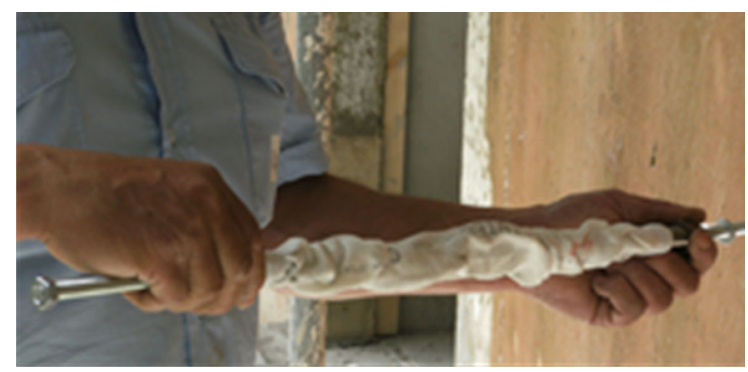

Fig. 2 The steel rod connector with fabric sleeve before grout injection
$90 \%$ greater than the diameter of the hole. Installation of the rod into the core-drilled hole (Fig. 3) was also followed by a pre-tensioning operation up to $10-20 \%$ of the rod yielding strength. Finally, the fabric sleeve was injected in pressure (2.5-5 atm, depending on the quality of the masonry material) using a high-strength ready-to-use cement-based grout. The effect of pretensioning and countersinking produced a confinement of the masonry material and increased the level of connection between wall leaves (Fig. 3). The fabric sleeve avoided unexpected scattering and wastefulness of the grout between the masonry. Thanks to its flexibility, it could expand, moulding itself into the shape and voids within the walls, providing mechanical bond. Although the use of cement is generally detrimental in heritage structures due to its scarce compatibility with historic masonry, the cement-based grout provided by the producer was still used here for the tests. In fact, the fabric sleeve encasing the anchor did not allow the cement-based grout to spread freely within the masonry, thus largely limiting the used quantity. The grout's mechanical and thixotropic properties and its low porosity also guaranteed the needed characteristics for the transmission of the loads between the masonry leaves.

The anchoring system relies on mechanical interlocking between connector and masonry substrate; as a consequence, at the end of the installation procedure, no front plates were needed and the disruption to the architectural features was maintained to a minimum.

As stated, the effectiveness of the method can be improved further by pre-tensioning the connectors allowing the reinforcement to act as an "active system," able to be engaged even for service loads and for low-intensity seismic activity, providing extra tensile strength to the masonry material. Therefore, for the steel rods used in this study, a pre-tensioning level of approximately $10 \%$ of the ultimate rod strength was used. An interesting feature was also that the reinforcing system is based on the use of materials easy to find on the construction market (threaded stainless steel rods, fabric sleeve, cement-based grout).

This reinforcement technique has been recently applied on two listed stone masonry buildings in Italy [32]. However it can be used equally on regularly shaped (perfectly cut stone masonry, or brickwork) walls or irregular (rubble or pebble stone masonry) walls made of natural stone blocks of various sizes and shapes. 
Fig. 3 Detail of the $16 \mathrm{~mm}$-diameter connector (dimensions in $\mathrm{mm}$ )

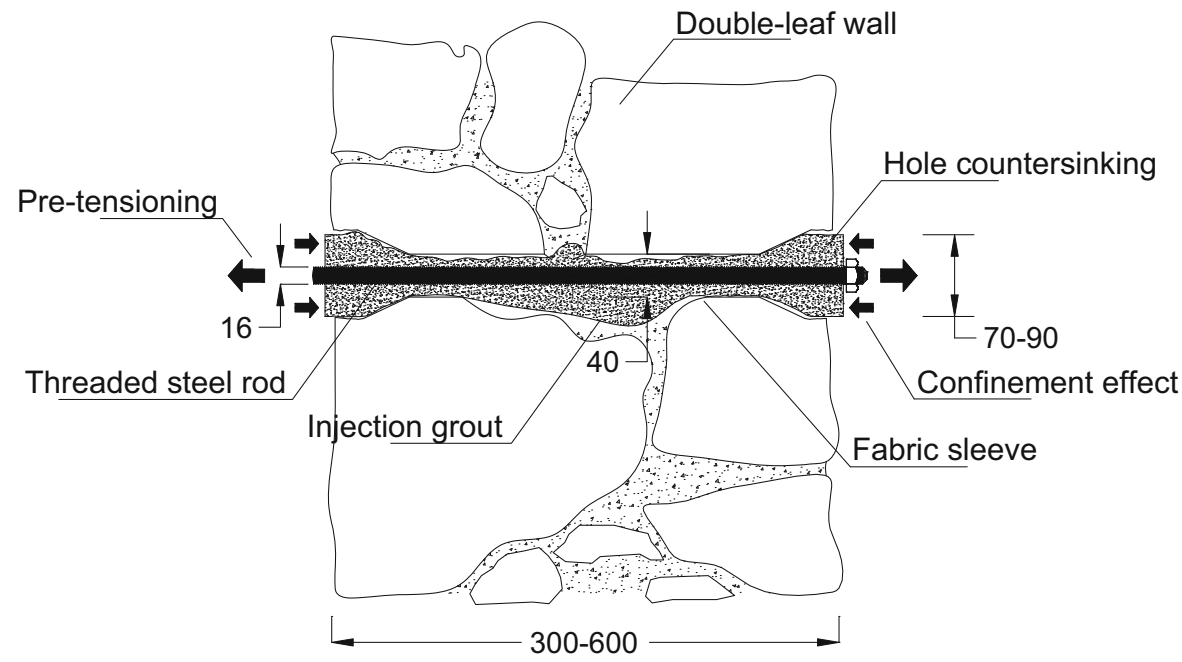

\section{Experimental program}

Tests were carried out on site and in the laboratory, with the aim of analyzing the behavior of multi-leaf stone masonry wall panels retrofitted with transverse connectors. Several pull-out tests were conducted on site on full scale wall panels. Finally four full scale wall panels were constructed in the laboratory for the purpose of this investigation from solid calcareous stone and weak cement-based mortar.

\subsection{Material specification}

For stainless steel rods, tensile ultimate and yield strength were measured using an Instron push-pull testing machine on 14 samples (six $12 \mathrm{~mm}$-diameter and eighth $20 \mathrm{~mm}$-diameter samples): the mean $0.2 \%$ offset yield strength was $434.9 \mathrm{MPa}$ (root-mean-square deviation $(\mathrm{SD})=28.5 \mathrm{MPa})$ and the ultimate tensile strength 697.1 MPa (SD = 44.6 MPa) (Table 1).

For the ready-to-use cement-based grout, the compressive strength at an age of 28 days and Young's modulus, as stated in the producer data sheet, were 51.5 and 28,537 MPa, respectively. This was a thixotropic grout with a low water/cement ratio (0.24).

For the laboratory tests barely cut calcareous stones were adopted in the construction of the wall panels. Eight cylindrical samples of $80 \mathrm{~mm}$ diameter and $150 \mathrm{~mm}$ height of the used stone, tested according to ASTM C67 [33], gave a mean compressive strength of $42.73 \mathrm{MPa}$ and SD of 5.7 MPa. The stone material had a weight density of $22.40 \mathrm{kN} / \mathrm{m}^{3}$.
The mortar mix design used for the construction of the wall panels in the laboratory was established as 12:5:1 (sand:lime:cement). Eighteen compression tests have been conducted on the mortar in accordance with ASTM C349 [34]. The mortar had a compressive strength of $1.92 \mathrm{MPa}$ and a SD of $0.273 \mathrm{MPa}$. Nine mortar prisms were also tested in bending according to ASTM C348 [35]; the prisms dimensions were $40 \times 40 \times 160 \mathrm{~mm}^{3}$ and the bending strength was $0.292 \mathrm{MPa}(\mathrm{SD}=0.059 \mathrm{MPa})$.

\subsection{Test setup}

\subsubsection{On site testing}

Pull-out tests, which measured the force required to pull out a connector inserted in a stone masonry wall, were used to investigate the connector/masonry substrate bond behavior. The tests were performed using a hydraulic hollow jack connected to a manual pump. The pullout test apparatus comprised a loading system made of a $300 \mathrm{kN}$ capacity hydraulic hollow cylinder mounted on heavy duty spreader steel beam. Test was conducted using a load controlled pump with a constant rate of approx. $5 \mathrm{kN} / \mathrm{min}$. The end of each connectors was fixed to the hollow jack and this acted at midpoint of the spreader steel beam supported over a $1100 \mathrm{~mm}$ span. Specimens horizontal extension was measured with one linear variable differential transformer (LVDT) over a gage length of $50 \mathrm{~mm}$, mounted on a purpose made steel frame. A precision measuring Bourdon gauge was used to measure oil 
pressure. Both oil pressure and deformation were digitally recorded using a four channel data acquisition system operating at a frequency of $0.1 \mathrm{~Hz}$.

Twelve pull out tests were conducted on site on 4 pre-existing stone masonry wall panels. Buildings in stone are common in many parts of Europe, as they increasingly replaced buildings in clay, timber and thatch from the beginning of fourteenth century. Masonry was made of barely cut stones or pebbles bonded together using a weak lime-based mortar. A single letter designation was used for each masonry typology. Panels were selected from four different existing buildings in Italy and were double- (typologies B and C) or triple-leaf (with rubble core) (typologies A and D) walls. Masonry typologies A and B were made of large barely cut stones (larger dimension up to $45 \mathrm{~cm}$ ), while small stones and pebbles (larger dimension up to $20 \mathrm{~cm}$ ) were used for typologies C and D. All stones were made of calcareous sediments with high weight density $\left(>22.00 \mathrm{kN} / \mathrm{m}^{3}\right)$ and high compressive strength ( $>40 \mathrm{MPa})$.

Diameters of the hole were 40 or $64 \mathrm{~mm}$, depending on the wall thickness (typically $30 \mathrm{~mm}$ up to $30 \mathrm{~cm}$ wall thickness, 40 and $60 \mathrm{~mm}$ for wall thicknesses up to 50 and $80 \mathrm{~cm}$, respectively). A compressed air line was used for hole cleaning and water was removed as completely as possible. Tests were carried out at 28 days after grout injection into the fabric sleeve.

\subsubsection{Laboratory testing}

Two series of experiments were also carried out in the laboratory. Four wall panels were subjected to shear and compression tests. The wall panels tested in the laboratory were similar to the ones tested on site. All specimens were made of stone masonry, double- or triple-leaf walls, using a weak mortar. For shear tests, two full-scale wall panels were built in the laboratory with a triple-leaf thickness. The dimensions of the panels (Panels No. 1 and 2) were $0.45 \times 0.88 \times$ $0.88 \mathrm{~m}^{3}$ (thickness $\times$ width $\times$ height). Qualified masons were hired to build the panels, using the traditional historic technique for stone bonding in central Italy. This consists in setting the larger stones with their longest dimension perpendicular to the wall face working on both external leaves and in inserting smaller ones into the inner rubble core. In order to study the effectiveness of the transverse connectors, external masonry leaves rested on timber prisms and the inner rubble core was loaded by the application of a compression force on the top of the panel. A drawing of the test setup is shown in Fig. 4. A 50-tons hydraulic jack was applied centrally to generate the vertical compression load on the inner rubble core. A steel H-shaped beam (flange's width $=100 \mathrm{~mm}$ ) was inserted between the jack and the panel to achieve a uniform distribution of the vertical load along the panel's width. The width of both the panel and the steel beam was $0.88 \mathrm{~m}$. The two wall panels were loaded at a rate of approximately $4 \mathrm{kN} / \mathrm{min}$ up to failure. The deflection of the inner core-critical to structural assessment-was obtained with contact instrumentation. Six LVDTs were used to measure the deformations of the three masonry leaves. Two more LVDTs were placed horizontally near the leaf's centroid to monitor the out-of-plane movements. All deflection measurements were logged continuously by LVDTs and readings included panel load and 8 LVDT over the duration of the test. Figure 5a shows the position of the transverse connectors used for shear testing.

The effect of the connectors as a means of increasing the wall's axial capacity was also studied by performing uniaxial compression tests on two fullscale double-leaf wall panels. Again, laboratory panels were similar to the ones tested on site for used materials and stone arrangement. The main difference was that the thickness of laboratory wall panels was smaller than the one of on site walls. This has been done with aim to study the "buckling behavior" of the laboratory panels and analyze the contribution of the connectors. The intention was to conduct compression tests on both reinforced and unreinforced specimens in order to verify the structural performance of the reinforcement and to compare results with theoretical formulations. The wall panels (thickness $\times$ width $\times$ height $=0.22 \times 0.71 \times 1.45 \mathrm{~m}^{3}$ ) were tested in the laboratory with nominally identical support conditions. The compression tests were carried out using a single H-shaped steel profile (flange's width $=250 \mathrm{~mm}$ ) centrally placed over the wall panel in order to guarantee a uniform distribution of the compression load along the width. Thus, wall Panel No. 3 was first tested without connectors, and finally repaired by the application of six connectors and re-tested with the same testing conditions. A further panel (No. 4) was tested after having been 
Table 1 Mechanical characteristics of materials

${ }^{a}$ Bending strength

b Offset yield point $0.2 \%$

\begin{tabular}{lllll}
\hline & Mortar & Grout & Stone & Stainless steel rod \\
\hline Sample size & 18 & 9 & 8 & $6+8$ \\
Young's modulus $(\mathrm{GPa})$ & - & 28.54 & - & 219.2 \\
Weight density $\left(\mathrm{kg} / \mathrm{m}^{3}\right)$ & - & - & 2287 & - \\
Compressive strength $(\mathrm{MPa})$ & 1.92 & 52.34 & 42.73 & - \\
Yield strength $(\mathrm{MPa})^{\mathrm{b}}$ & - & - & - & 434.9 \\
Tensile strength $(\mathrm{MPa})$ & $0.292^{\mathrm{a}}$ & $2.31^{\mathrm{a}}$ & - & 697.1 \\
Sample dimensions $(\mathrm{mm})$ & $40 \times 40 \times 160$ & $40 \times 40 \times 160$ & - & - \\
Sample diameter $(\mathrm{mm})$ & - & - & 80 & $12 / 20$ \\
\hline
\end{tabular}

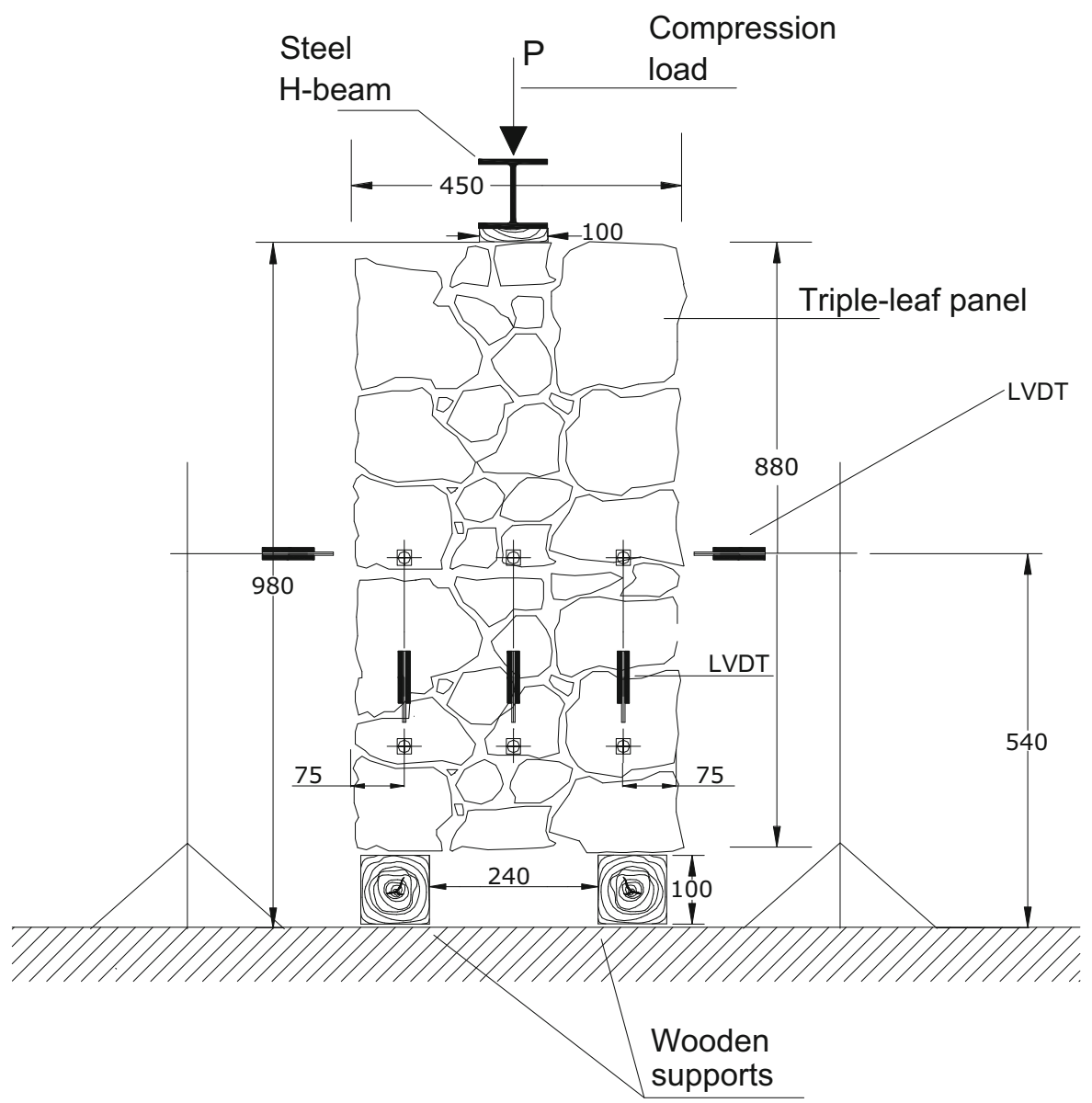

Fig. 4 Shear test arrangement (dimension in $\mathrm{mm}$ )

reinforced according to the same arrangement used to repair Panel No. 3 (Fig. 5b).

An alpha-numeric designation has been adopted for each laboratory test: a progressive number is used for each test and the letter designations Un, Rp, Rf have been used to identify unreinforced, repaired and reinforced (virgin) panels, respectively.

\section{Test results}

\subsection{Pull-out tests (on site)}

The capacity of the transverse connectors to bond together masonry leaves is mainly due to the mechanical interlocking with masonry. By performing pull out 


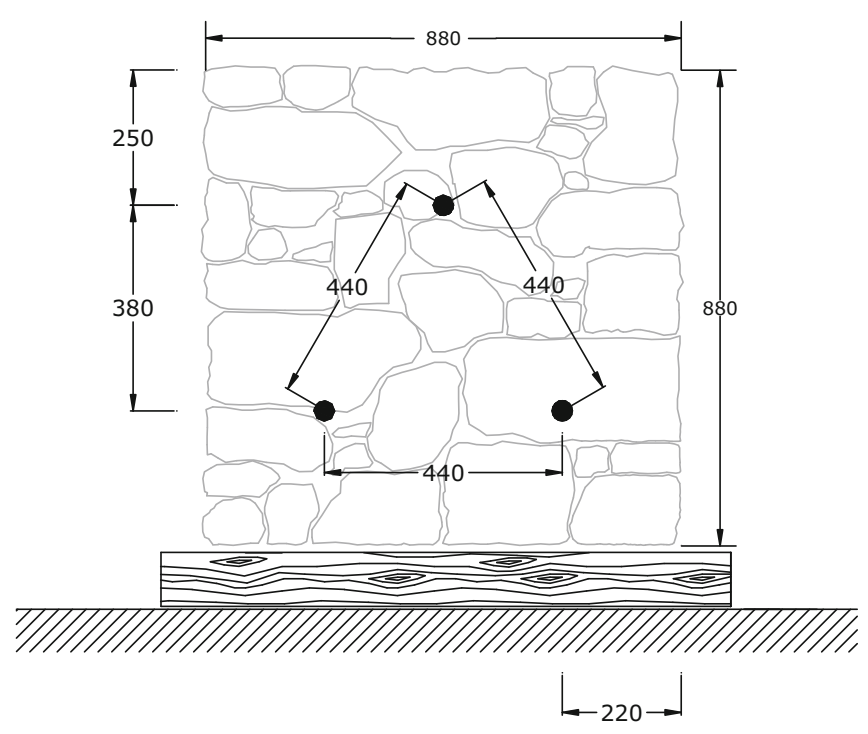

(a)

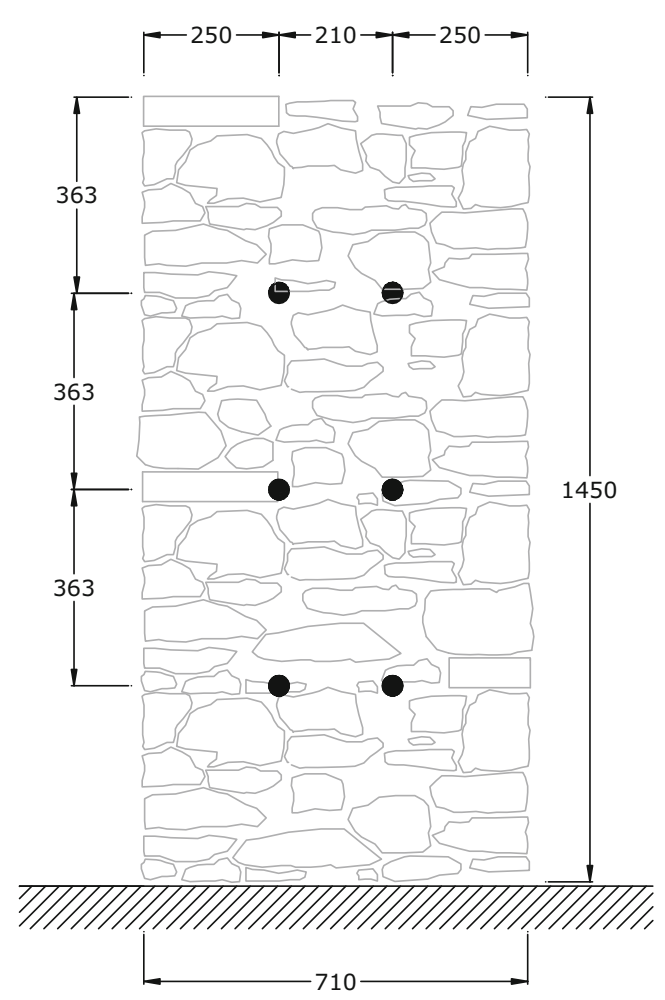

(b)

Fig. 5 Arrangement of connectors: a shear test. b Compression test (dimensions in $\mathrm{mm}$ )

tests, it was possible to evaluate this parameter and the load bearing characteristics of the injected anchors. During pull out tests forces were transmitted by bond between the anchor and the surrounding material until failure was reached.

Table 2 shows the tests results in terms of pull-out (maximum) load and shear stress for the different stone masonry typologies investigated. Shear stress values were calculated assuming a uniform distribution on the effective bond length at the interface between masonry and fabric sleeve. For masonry typologies A, C and D failure occurred due to masonry cracking in the area surrounding the hole. Radial cracks gradually opened from the hole both in the mortar joints and in the stones (Fig. 6). A small horizontal displacement of a cylindrical portion of masonry material (typically $200-250 \mathrm{~mm}$ in diameter) in the direction of the pull-out force was also noted. By comparing the magnitudes of the pull-out stress (up to $516 \mathrm{MPa}$ ) with the rod's yield and ultimate strengths (434.9 and 697.1 MPa, respectively), it can be noted that these values are similar and this indicates that the rod's tensile mechanical properties have been fully exploited due to the activation of the mechanical interlocking at interface masonry/fabric sleeve. With regard to masonry typology B, the rod's yield strength has been attained with no masonry failure.

In conclusion the performance of the injected anchors was strongly affected by the parent masonry material properties, as it is shown by the scattering of results, but the high values of the pull out loads demonstrated that the connector was able to effectively bond together the adjacent wall leaves. Table 2 also gives the results in terms of bonding stress at interface between sleeve-masonry. This value was calculated by dividing the pull-out force by the lateral hole's surface. Because the Young's modulus of the grout was much greater compared to the Young's modulus of the parent masonry material, when a pullout force was applied on the connector the deformation mainly occurred in the masonry material and a uniform distribution of bond stresses was believed to be an acceptable assumption. 
Table 2 Results of pull-out tests

\begin{tabular}{lllllll}
\hline $\begin{array}{l}\text { Masonry } \\
\text { typology }\end{array}$ & $\begin{array}{l}\text { Rod diameter } \\
(\mathrm{mm})\end{array}$ & $\begin{array}{l}\text { Hole diameter } \\
(\mathrm{mm})\end{array}$ & $\begin{array}{l}\text { Hole depth } \\
(\mathrm{mm})\end{array}$ & $\begin{array}{l}\text { Mean pull out } \\
\text { load }(\mathrm{kN})\end{array}$ & $\begin{array}{l}\text { Mean shear stress } \\
(\mathrm{MPa})\end{array}$ & Failure type \\
\hline A & 16 & 40 & 550 & 103.8 & 1.51 & $\begin{array}{c}\text { Masonry failure and rod } \\
\text { yielding } \\
\text { Rod yielding }\end{array}$ \\
B & 20 & 64 & 600 & 226.5 & 1.88 & Masonry failure \\
C & 16 & 40 & 450 & 44.5 & 0.78 & 1.32 \\
D & 20 & 64 & 550 & 146.2 & Masonry failure \\
\hline
\end{tabular}

Using hole's lateral surface

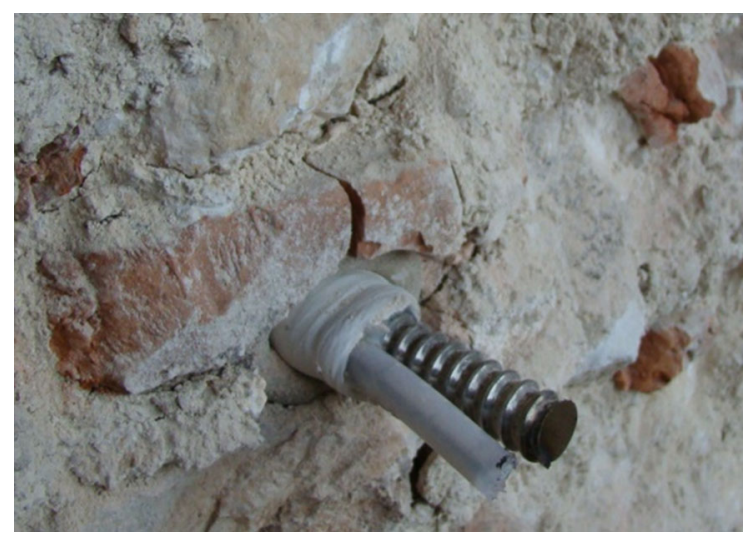

Fig. 6 Typical masonry failure mode during pull-out tests

\subsection{Shear tests (laboratory)}

Two full-scale masonry wall panels were built in the laboratory for shear tests. Each panel was made of a triple-leaf wall and the inner core was loaded in compression in order to study the shear response of the adjacent masonry leaves (Fig. 4).

Results of unreinforced Panel 1Un clearly demonstrated that the vertical planes between masonry leaves were critical for the overall behavior of a triple-leaf wall. Mechanical interlocking was not able to prevent the separation between masonry leaves. A maximum compression load $P_{\max }$ of $34.11 \mathrm{kN}$ was recorded (Table 3). Failure was by splitting of the inner rubble core from one of the two external wall leaves. The failure occurred progressively in a non-brittle manner: a vertical crack opened near the point of application of the load and propagated toward the wall base (Fig. 7).

The different magnitudes of the horizontal displacement highlight the non-symmetric distribution of the vertical load between the wall leaves due to a weak transverse connection.

Horizontal displacements were measured, using 2 LVDTs over a gage length of $100 \mathrm{~mm}$, at each leaf centroid (i.e. at interception of the panel diagonals). The two external wall leaves of the unreinforced panel deformed differently with maximum horizontal displacements of 4.33 and $1.15 \mathrm{~mm}$. At failure the horizontal displacement of one external leaf was 3.76 times bigger than the other.

By assuming a uniform distribution, the average shear stress at failure is given by:

$\tau_{\mathrm{r}}=\frac{P_{\max }}{2 \times S}$

where $S$ in the area of the contact surface between adjacent masonry leaves. For Panel $1 \mathrm{Un} \tau_{\mathrm{r}}$ was $0.0222 \mathrm{MPa}$.

The application of three transverse connectors (Fig. 5a) produced an interesting effect both in terms of load and deformation capacity: Panel 2Rf has been tested after being retrofitted and a compressive maximum load $P_{\max }$ of $109.43 \mathrm{kN}$ was recorded (Table 3). This is an increment of 3.21 compared to the load capacity of the unreinforced panel (Panel $1 \mathrm{Un})$. The leaf response in terms of vertical and horizontal deflections was more symmetric and the difference between leaf deflections at failure was approx. only $15 \%$.

Because the presence of the connectors produced a point-contribution, results presented in Table 3 should be considered with caution as the effect of connectors is measured in terms of increments in average shear stress. However the resulting trend looks quite clear and gives an interesting indication of the effectiveness of the presence of the connectors. 
Table 3 Results of shear and compression tests

\begin{tabular}{lllllll}
\hline & $\begin{array}{l}\text { No. of } \\
\text { connectors }\end{array}$ & $\begin{array}{l}\text { Rod and hole } \\
\text { diameter }(\mathrm{mm})\end{array}$ & $\begin{array}{l}\text { Maximum load } \\
P_{\max }(\mathrm{kN})\end{array}$ & $\begin{array}{l}\text { Shear stress } \tau_{\max } \\
(\mathrm{MPa})\end{array}$ & $\begin{array}{l}\text { Compression stress } \\
\sigma_{\max }(\mathrm{MPa})\end{array}$ & $\begin{array}{l}\text { Young's } \\
\text { modulus } E_{0.5} \\
E_{P_{\max }}(\mathrm{MPa})\end{array}$ \\
\hline Panel 1Un - & $20-40$ & 34.11 & 0.0222 & - & - \\
Panel 2Rf & 3 & $20-40$ & 109.43 & 0.0714 & - & - \\
Panel 3Un - & $12-30$ & 48.8 & - & 0.312 & 312.6 \\
Panel 3Rp 6 & $12-30$ & 91.1 & - & 0.583 & 359.3 \\
Panel 4Rf 6 & $12-30$ & 101.5 & - & 0.650 & 194.0 \\
\hline
\end{tabular}

$*$ For $\sigma_{2}=0.3 \mathrm{MPa}$

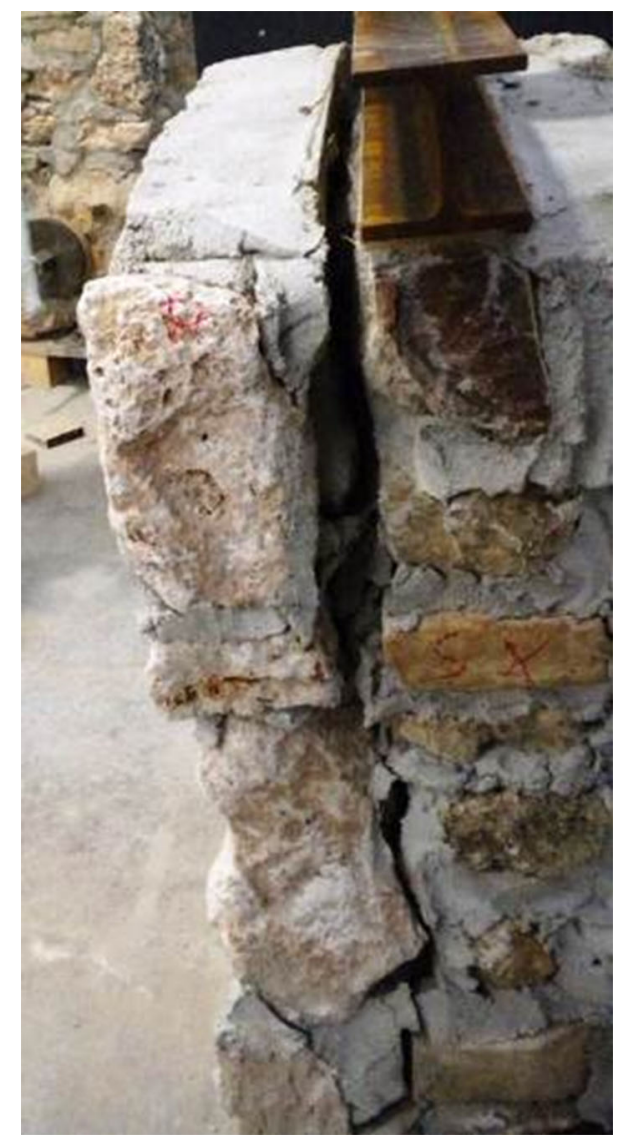

Fig. 7 Failure mode (unreinforced panel)

Also the magnitudes of the horizontal deflections of external leaves (maximum displacements $0.68 \mathrm{~mm}$ ) were smaller compared to the ones recorded for the unreinforced panel $(4.33 \mathrm{~mm})$ (Panel 1Un). The two external wall leaves also exhibited similar maximum horizontal displacements: 0.61 and $0.68 \mathrm{~mm}$, with a ratio of 1.11 , significantly smaller compared to the one calculated for the unreinforced panel (3.76). This effectively demonstrated the more monolithic behavior of the triple-leaf wall panel after reinforcement.

The failure mode of the reinforced panel (Panel 2Rf) was also different. The presence of the transverse connectors prevented the separation of the adjacent masonry leaves and vertical cracks opened both on the panel's façade and on its lateral section, highlighting the effective contribution given by the connectors.

\subsection{Compression tests (laboratory)}

Positive indications of the effectiveness of the transversal connectors to bond double-leaf walls (Fig. 8) were obtained from the results of three compression tests. The first test, carried out on an unreinforced panel (Panel 3Un), failed for a compression load of $48.8 \mathrm{kN}$. The analysis of the vertical deformations (recorded using 4 LVDTs) clearly indicated that the two masonry leaves deformed differently: for panel's side B a maximum vertical strain of 0.0011 was recorded, while, for side A, this was only 0.0006 (Fig. 9). The ratio between the two strain values was 1.83 . The compression test showed that the two adjacent masonry leaves behaved differently and the difference in behavior tended to get bigger when the compression load increased as a consequence of the progressive detachment of the two masonry leaves. The opening of vertical cracks was the typical failure mode of a masonry member in compression. However no vertical cracks could be noted on the leaf's surface: this could be due to a buckling failure mode of the masonry leaves that anticipated the compressive one.

Panel 3 was also repaired by the application of 6 traverse connectors and tested again (Panel 3Rp) (Fig. 5b). The capacity of the panel increased to $91.1 \mathrm{kN}$ and a compression stress of $0.583 \mathrm{MPa}$ was 


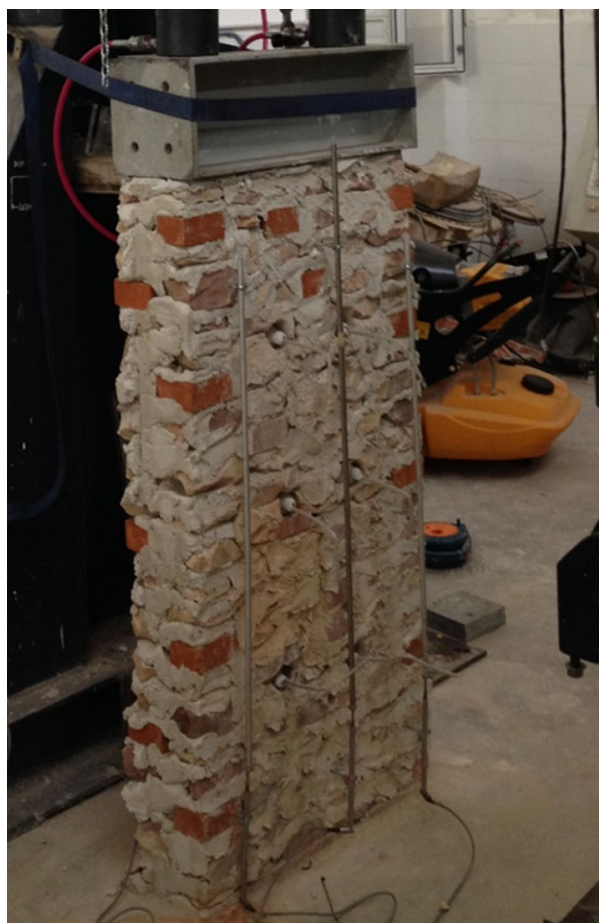

Fig. 8 Compression tests on reinforced panel 4Rf

calculated (Fig. 10). For this second test, vertical cracks mainly appeared on the leaf's surface highlighting a more-likely compressive failure. Scattering of vertical strains between wall leaves highly reduced indicating a monolithic behavior of the wall.

A third compression test was carried out on an undamaged panel (Panel 4Rf). This panel was identical to Panel 3 for dimensions, mortar type and masonry arrangement. The application of the connectors was an effective method to bond the masonry leaves and a compression load of $101.5 \mathrm{kN}(0.65 \mathrm{MPa}$

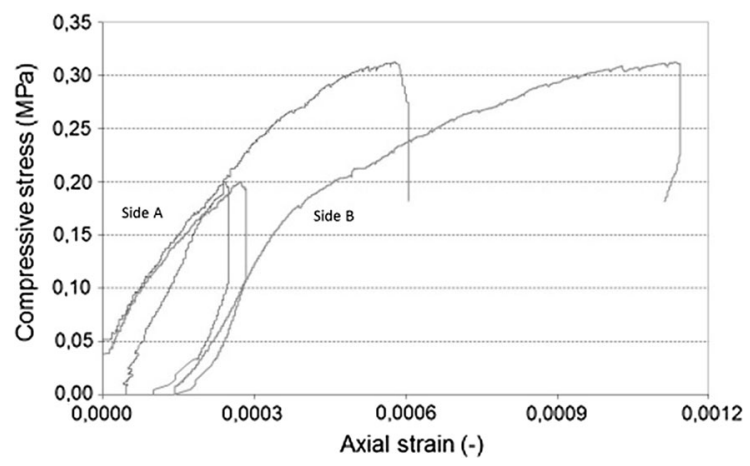

Fig. 9 Stress versus axial strain of masonry leaves for unreinforced panel $3 \mathrm{Un}$ in terms of compressive stress) was reached (Fig. 10). This was more than $108 \%$ greater compared to the control unreinforced wall panel. Again the failure occurred for the formation of vertical cracks on the leaf's surface. The analysis of the vertical deformations clearly showed the similar behavior between the two masonry leaves. For test on Panel 3Rp the magnitudes of the vertical strain at maximum load were 0.0030 and 0.0023 , for side A and B, respectively (with a ratio between the strain values of 1.3). For test on Panel 4Rf this ratio was only 1.03.

It is worth noting that the repaired wall panel responded differently from the retrofitted one that has not previously been loaded, with a smaller increment of the compression capacity $(+86.7$ and $+107.8 \%$ for repaired and reinforced panels, respectively). The application of the transverse connectors cannot restore the continuity of a cracked wall leaf, but can only increase the collaboration between weakly connected masonry leaves. However for both panels, repaired or reinforced by the use of transverse connectors, a substantial compression load increment has been recorded.

It could be interesting to compare the experimental results with the value of the critical load evaluated by performing a simple elastic buckling analysis in a cantilever column.

The critical load $P_{\mathrm{CR}}$ :

$P_{\mathrm{CR}}=\frac{\pi^{2} E A}{\lambda^{2}}$

where $E$ is the masonry Young's modulus, $A$ is the panel cross section $\left(710 \times 110 \mathrm{~mm}^{2}\right.$ for double-leaf and $710 \times 220 \mathrm{~mm}^{2}$ for a single-leaf wall), $\lambda$ is the slenderness ratio given by:

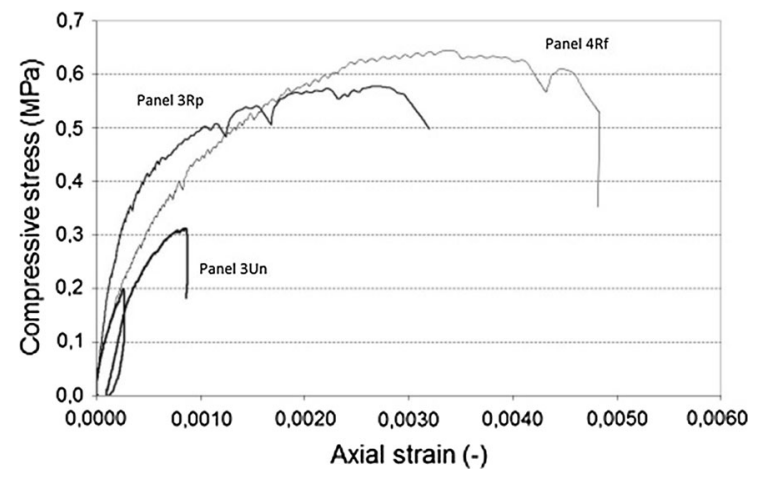

Fig. 10 Stress versus axial strain: comparison between the three compression tests 
$\lambda=\frac{L_{\mathrm{eff}}}{\rho_{\mathrm{min}}}$

where $L_{\text {eff }}$ is equal to twice the height of the wall panel $(2900 \mathrm{~mm})$ and $\rho_{\min }$ is the minimum radius of gyration of the panel cross Section $(31.75 \mathrm{~mm}$ for a double-leaf wall or $63.5 \mathrm{~mm}$ for a single-leaf wall). In order to take into account the non-linear behavior of masonry in compression, the value of the Young's modulus $E$ used in Eq. (1) was calculated from the $\sigma-\varepsilon$ graph by considering the slope of the secant line between 0.01 and $0.5 \mathrm{MPa}\left(\sigma_{1}\right.$ and $\left.\sigma_{2}\right)$ :

$E_{0.5}=\frac{\sigma_{2}-\sigma_{1}}{\varepsilon_{\sigma_{2}}-\varepsilon_{\sigma_{1}}}$

where $\varepsilon_{\sigma_{2}}$ and $\varepsilon_{\sigma_{1}}$ are the corresponding values of the axial vertical strain.

Table 3 also shows the values of the flexural stiffness $E_{P_{\max }}$ at $P_{\text {max }}$.

This simplified analysis shows that the critical loads $P_{\mathrm{CR}}$ are 66 and $266 \mathrm{kN}$ for a wall made of two $110 \mathrm{~mm}$-thick leaves and for a $220 \mathrm{~mm}$-thick singleleaf wall, respectively. The value of $66 \mathrm{kN}$ is not far from the result on the unreinforced wall panel 1Un $(48.8 \mathrm{kN})$, indicating that buckling problems govern the behavior of this panel under compression. On the other hand, the large difference between the critical load value of the simplified calculation $(266 \mathrm{kN})$ and experimental results (91.1 and $101.5 \mathrm{kN}$ ) indicates that buckling is not anymore governing the compression test. For these tests, failure was mainly produced by attaining the masonry compressive strength.

Since the number of specimens tested was limited, results should be confirmed by a larger experimental programme. However, experimental evidence has been given about the effectiveness of the application of transverse connectors both on repaired and virgin double-leaf wall panels to effectively bond adjacent masonry leaves and significantly increase the panel's capacity in compression. By applying the connectors, it was possible to relate the panel's compressive capacity only to the masonry compressive strength.

\section{Design procedures}

The reinforcement of a double-leaf wall panel using transverse connectors can be approached considering the out-of-plane (overturning) mechanism of the masonry wall and using a simplified equilibrium analysis to evaluate the collapse-load factor $a$. This is a typical loading condition for a wall panel subjected to an horizontal seismic action.

By assuming a monolithic (solid) behavior for each masonry wall leaf, the moment $M_{\mathrm{R}(\mathrm{A})}$ causing the overturning of the wall about the center of rotation at the base of the wall panel is:

$M_{\mathrm{R}(\mathrm{A})}=a\left(W \times y_{G}+F_{\mathrm{V}} \times h_{\mathrm{V}}+P_{\mathrm{S}} \times h\right)$

where $W$ is the total weight of the masonry wall panel and $y_{\mathrm{G}}$ is the distance of the panel's centroid from the center of rotation at the panel base. $F_{\mathrm{V}}$ is the dead vertical load due to the presence of a floor; $h_{\mathrm{v}}$ is the vertical distance between the point of application of load $F_{\mathrm{V}}$ and the center of rotation; $P_{\mathrm{S}}$ is the weight of the roof; $h$ is the wall height.

The resisting moment $M_{\mathrm{S}(\mathrm{A})}$, withstanding the panel rotation, is given by the following:

$M_{\mathrm{S}(\mathrm{A})}=W \times \frac{s}{2}+F_{\mathrm{V}} \times d_{\mathrm{V}}+P_{\mathrm{S}} \times d$

where $s$ is the wall panel thickness, $d_{\mathrm{V}}$ and $d$ are the horizontal distances from the point of application of the corresponding load to the center of rotation at the panel base.

At equilibrium:

$M_{\mathrm{S}(\mathrm{A})}=M_{\mathrm{R}(\mathrm{A})}$.

Thus, the value of the collapse-load factor $(a)$ is:

$a=\frac{\left(W \times \frac{s}{2}+F_{\mathrm{V}} \times d_{\mathrm{V}}+P_{\mathrm{S}} \times d\right)}{\left(W \times y_{\mathrm{G}}+F_{\mathrm{V}} \times h_{\mathrm{V}}+P_{\mathrm{S}} \times h\right)}$.

Only if the overall behavior of the wall panel is monolithic (with no leaf detachment or slippage), the collapse-load factor is given by Eq. (2). As a consequence, this equation gives an upper bound of the factor for a retrofitted or single-leaf wall panel. The diameter of the connector and the number of connectors per $\mathrm{m}^{2}$ depends on the quality of the masonry, wall thickness and magnitude of the loads. A simplified design approach of the connector can be used by assuming that the vertical loads from existing floors and roof are acting only on one leaf (usually the indoor one) and by using this value as a shearing force acting on the transverse connectors, but this assumption needs to be assessed on a case to case basis. 
For a double-leaf wall (Fig. 11), by assuming a frictionless surface between adjacent masonry leaves (no mechanical interlocking or chemical bonding), the lower bound of the collapse-load factor $a$ is:

$$
\begin{aligned}
a= & \frac{\left(W_{\mathrm{A}} \times \frac{s_{\mathrm{A}}}{2}+W_{\mathrm{B}} \times \frac{s_{\mathrm{B}}}{2}\right)}{\left[\left(W_{\mathrm{A}}+W_{\mathrm{B}}\right) \times y_{\mathrm{G}}+F_{\mathrm{V}} \times h_{\mathrm{V}}+\left(P_{\mathrm{SA}}+P_{\mathrm{SB}}\right) \times h\right] \times 2} \\
& +\frac{\left(P_{\mathrm{SA}} \times d_{\mathrm{A}}+P_{\mathrm{SB}} \times d_{\mathrm{B}}+F_{\mathrm{V}} \times d_{\mathrm{V}}\right)}{\left(W_{\mathrm{A}}+W_{\mathrm{B}}\right) y_{\mathrm{G}}+\left(P_{\mathrm{SA}}+P_{\mathrm{SB}}\right) h}
\end{aligned}
$$

where the subscript letter designations $\mathrm{A}$ and $\mathrm{B}$ are used to identify the outdoor and indoor masonry leaf, respectively; $s$ and $W$ are the leaf thickness and weight. $P_{\mathrm{SA}}$ and $P_{\mathrm{SB}}$ are the vertical loads produced by the portions of the total weight of the roof, resting on leaf $\mathrm{A}$ and $\mathrm{B}$, respectively.

The use of a frictionless surface is a very conservative assumption for this analysis and particular attention should be paid. However experimental and theoretical results demonstrate that this is not far from truth.

The application of the reinforcement may cause a significant increase of the collapse-load factor up to

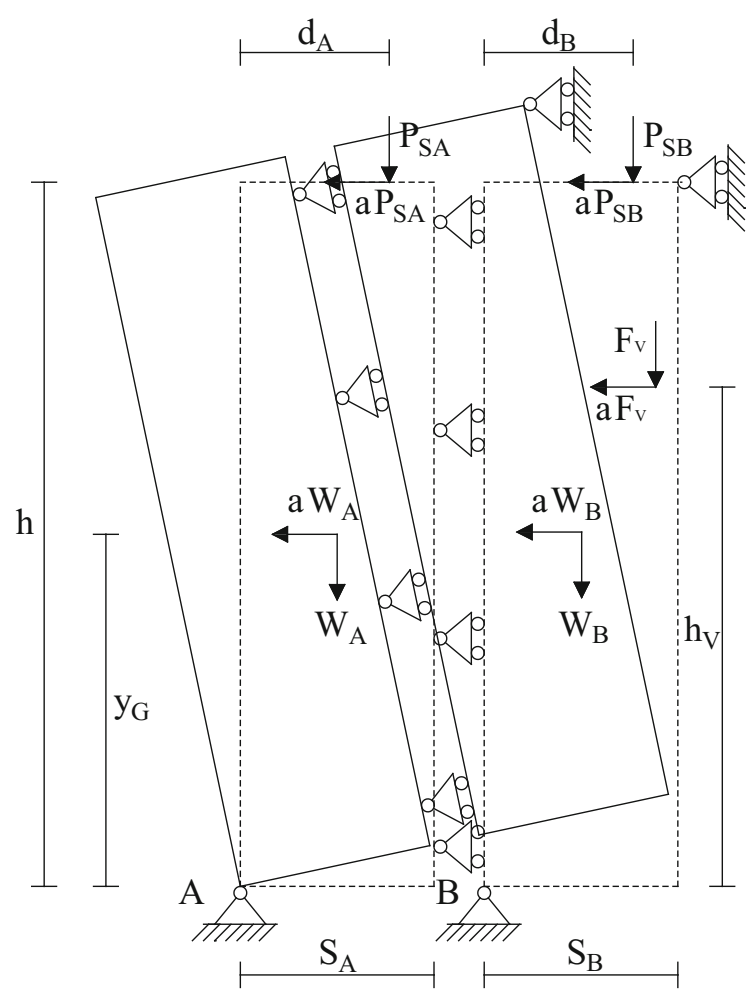

Fig. 11 Behavior of an unreinforced double-leaf wall
$300 \%$, shifting from the value given by (9) to the one in (8) depending on the geometry of the wall panel and on the loading conditions.

\section{Conclusions}

Connection between masonry wall leaves often proves to be a critical aspect in achieving an adequate reduction of the seismic vulnerability and in controlling the structural response during seismic events. Recent earthquakes continue to demonstrate the importance of the grade of connection of wall leaves especially for preventing out-of-plane collapse mechanisms.

The following summarizes the conclusions of the research available at this stage:

- The effectiveness of transversal artificial connectors inserted into multi-leaf stone masonry wall panels was experimented through pull out, shear and compression tests carried out on site and in the laboratory;

- The application of the connectors produced a substantial improvement to the seismic performance of the wall panels without significant alteration to the wall integrity;

- Pull out test results demonstrated that mechanical interlocking between the connector and the masonry substrate may effectively enhance the level of connection between adjacent masonry leaves.

- The results of the performed test programme proved that the use of transversal connectors is a promising retrofitting technique for historic masonry walls subjected to out-of-plane actions or compressive loads. The research results showed that shearing loads can be effectively redistributed between masonry leaves by inserting transverse connectors.

- The retrofitted wall panels showed additional compression capacity with increments up to a maximum of $107.8 \%$ compared to the control wall. The application of the connectors changed the panel's failure mode from buckling of the thin masonry leaves to vertical cracking.

- The repaired wall responded differently from the retrofitted wall that has not previously been loaded, with a smaller increment of the compression 
capacity. However for both panels repaired or reinforced by the use of transverse connectors, a substantial load increment was recorded.

Acknowledgements The authors wish to record their indebtedness to Prof M. Candela, Mr R. Savelli and Dr R. Fonti for their contribution to part of the experimental work. The authors also express their gratitude to Bossong (Bergamo, Italy) for providing the connectors.

Funding This study was funded by the Italian Ministry of Education [ReLUIS (2010-2013) Linea 2.3.1].

\section{Compliance with ethical standards}

Conflict of interest The authors declare that they have no conflict of interest.

Open Access This article is distributed under the terms of the Creative Commons Attribution 4.0 International License (http:// creativecommons.org/licenses/by/4.0/), which permits unrestricted use, distribution, and reproduction in any medium, provided you give appropriate credit to the original author(s) and the source, provide a link to the Creative Commons license, and indicate if changes were made.

\section{References}

1. Tassios PT (1988) Meccanica delle murature. Liguori Publications, Napoli (Italian Translation)

2. D'Ayala DF, Paganoni S (2011) Assessment and analysis of damage in L'Aquila historic city centre after 6th April 2009. Bull Earthq Eng 9(1):81-104

3. Lourenço PB, Mendesa N, Ramosa LF, Oliveira DV (2011) Analysis of masonry structures without box behavior. Int $\mathrm{J}$ Archit Herit 5(4-5):369-382

4. Kržan M, Gostič S, Cattari S, Bosiljkov V (2015) Acquiring reference parameters of masonry for the structural performance analysis of historical buildings. Bull Earthq Eng 13(1):203-236

5. Tomazevic M, Weiss P, Velechovsky T, Apih V (1991) The strengthening of stone masonry walls with grouting. Structural repair and maintenance of historical buildings. Vol 2: dynamics, stabilisation and restoration. Computational Mechanics Publication, Southampton, pp 215-225

6. Vintzileou E, Tassios TP (1995) Three-leaf stone masonry strengthened by injecting cement grouts. J Struct Eng 121(5):848-856

7. Vintzileou E, Miltiadou-Fezans A (2008) Mechanical properties of three-leaf stone masonry grouted with ternary or hydraulic lime based grouts. Eng Struct 30(8):2265-2276

8. Corradi M, Tedeschi C, Binda L, Borri A (2008) Experimental evaluation of shear and compression strength of masonry wall before and after reinforcement: deep repointing. Constr Build Mater 22:463-472
9. Valluzzi MR, Da Porto F, Modena C (2004) Behavior and modeling of strengthened three-leaf stone masonry walls. Mater Struct 37(3):184-192

10. Stratford T, Pascale G, Manfroni O, Bonfiglioli B (2004) Shear strengthening masonry panels with sheet glass-fiber reinforced polymer. J Compos Constr 8(5):434-443

11. Frumento S, Giovinazzi S, Lagomarsino S, Podestà S (2006) Seismic retrofitting of unreinforced masonry buildings in Italy. In: Proceedings of New Zealand Society for Earthquake Engineering Conference, Napier

12. Roca P, Araiza G (2010) Shear response of brick masonry small assemblages strengthened with bonded FRP laminates for in-plane reinforcement. Constr Build Mater 24:1372-1384

13. Borri A, Castori G, Corradi M, Sisti R (2014) Masonry wall panels with GFRP and steel-cord strengthening subjected to cyclic shear: an experimental study. Constr Build Mater 56:63-73

14. Egermann R, Newald-Burg C (1994) Assessment of the load bearing capacity of historic multiple leaf masonry walls. Proceedings of 10th international brick and block masonry conference. Calgary, Canada, pp 1603-1612

15. De Felice G, Giannini R (2001) Out-of-plane seismic resistance of masonry walls. J Earthq Eng 5(2):253-271

16. Griffith MC, Magenes G, Melis G, Picchi L (2003) Evaluation of out-of-plane stability of unreinforced masonry walls subjected to seismic excitation. J Earthq Eng 7(1):141-169

17. De Felice G (2004) Out-of-plane fragility of historic masonry walls. In: Proceedings of the 4th international conference on structural analysis of historical constructions, vol. 2. Balkema, Padova, pp 1143-1148

18. Oliveira DV, Lourenço PB (2006) Experimental behaviour of three-leaf stone masonry walls. In: Proceedings of the conference and brokerage event: the construction aspects of built heritage protection, Dubrovnik

19. Borri A, Corradi M, Castori G, De Maria A (2015) A method for the analysis and classification of historic masonry. Bull Earthq Eng 13:2647-2665

20. Rondelet JB (1834) Traité théorique et pratique de l'art de bâtir. Didot Frères, Fils et Cie, Paris

21. Giuffrè A (1991) Letture sulla meccanica delle murature storiche. Kappa, Rome

22. Azevedo J, Sincraian G, Lemos JV (2000) Seismic behaviour of blocky masonry structures. Earthq Spectra 16(2):337-365

23. Binda L, Penazzi D, Saisi A (2003) Historic masonry buildings: Necessity of a classification of structures and masonries for the adequate choice of analytical models. In: Proceedings of the 6th international symposium on computer methods in structural masonry, Computers \& Geotechnics Ltd., Rome, pp 168-173

24. Binda L, Pina-Henriques J, Anzani A, Fontana A, Lourenco PB (2006) A contribution for the understanding of loadtransfer mechanisms in multi-leaf masonry walls: testing and modelling. Eng Struct 28(8):1132-1148

25. Augenti N, Parisi F (2010) Learning from construction failures due to the 2009 L'Aquila, Italy, earthquake. J Perform Constr Facil 24(6):536-555

26. Gigla B (2004) Bond strength of injection anchors as supplementary reinforcement inside historic masonry. In: 
Proceedings 13th international brick and block masonry conference, Amsterdam

27. Modena C, Casarin F, Valluzzi MR, Da Porto F (2006). Codes of practice for architectural heritage in seismic zones. In: Proceedings of the 5th conference, structural analysis of historical constructions, New Delhi

28. Bozzano C, Podestà S, Scandolo L, Brignola A (2013) Prove di compressione diagonale su murature a due paramenti: l'influenza dei diatoni (in Italian). In: Proceedings of 15th Italian conference, ANIDIS, Padova

29. Candela M, Cattari S, Lagomarsino S, Rossi M, Fonti R, Pagliuca E (2012) In-situ test for the shear strength evaluation of masonry: the case of a building hit by L'Aquila earthquake (Italy). In: Proceedings of 15 th world conference on earthquake engineering, Lisbon

30. Casolo S, Milani G (2013) Simplified out-of-plane modelling of three-leaf masonry walls accounting for the material texture. Constr Build Mater 40:330-351
31. Pinho FF, Lúcio VJ, Baião MF (2014) Rubble stone masonry walls strengthened by three-dimensional steel ties and textile reinforced mortar render, under compression and shear loads. Int J Archit Herit 9(7):844-858

32. Candela M, Borri A, Corradi M, Righetti L (2016) Effect of transversal steel connectors on the behaviour of rubble stone-masonry walls: two case studies in Italy. In: Proceedings of 16th international brick and block masonry conference, Padova

33. ASTM C67 (2002) Standard test methods for sampling and testing brick and structural clay tile, West Conshohocken

34. ASTM C349 (2002) Standard test method for compressive strength of hydraulic cement mortars (using portions of prisms broken in flexure), West Conshohocken

35. ASTM C348 (2002) Standard test method for flexural strength of hydraulic-cement mortars, West Conshohocken 